\title{
What is depression in epilepsy?
}

\section{Christian E. Elger* and Christian Hoppe*}

Department of Epileptology, University of Bonn Medical Centre, Bonn, Germany

*Correspondence: christian.elger@ukb.uni-bonn.de; christian.hoppe@ukb.uni-bonn.de

\section{INTRODUCTION}

Psychiatry, in terms of neuropsychiatry, has experienced an impressive revival in the field of neurology over the past two decades. This especially holds true for epileptology (Reynolds and Trimble, 2009). A large number of studies have addressed depressive and other affective disorders in patients with seizures. Depression is now widely acknowledged as a frequent psychiatric comorbidity of seizure disorders (Barry et al., 2008; LaFrance et al., 2008).

Here we critically explore the concept of depression as a comorbidity in epilepsy (see also Hoppe and Elger, 2011). First, we address criteria which differentiate between transiently altered mood states and psychiatric mood disorders. We then show that depression in epilepsy provides a perfect model for the biopsychosocial etiology of depression and discuss related therapeutic approaches. Finally, we provide some general remarks on what is required to maintain or restitute emotional well-being in patients with therapy-refractory epilepsy.

\section{DEFINING DEPRESSION COMORBIDITY}

In this section, we make suggestions in order to clarify the concept of depression as a psychiatric comorbidity in epilepsy.

\section{MOOD REGULATION DISORDER}

Evidently, depressive mood per se is not sufficient for diagnosing a psychiatric disorder (Mula et al., 2008; Holtzheimer and Mayberg, 2011). For example, feeling blue is the adequate affective response to suffering (e.g., bereavement). Unfortunately, epilepsy and other severe chronic conditions provide too many opportunities to reasonably feel bad. So what distinguishes a mood disorder from altered but still normal mood?

We suggest defining affective disorders as disorders of mood regulation rather than alterations of mood state (Holtzheimer and Mayberg, 2011; Hoppe and Elger, 2011). This proposal clarifies established diagnostic criteria. For example, "loss of pleasure" is a key symptom of depressive disorders
(DSM-IV-TR, ICD-10) and signifies the absence of formerly shown positive affective responses to still pleasurable stimuli (i.e., altered mood regulation resulting in an inadequate affective response).

In otherwise healthy people, a sustained depressive mood lasting more than 2 weeks or so is probably inadequate (except in cases of bereavement or other similarly traumatic life events) and may therefore reasonably serve as a reliable indicator of mood dysregulation. However, in patients with severe chronic diseases such as epilepsy, things may look quite different. For these patients, the diagnostic focus should be set more explicitly on mood dysregulation - that is, on the inadequacy of the affective response with regard to the current life conditions and the patient's personality. Adjusting neuropsychiatric evaluation tools to the conditions of a chronic disease might alter the prevalence estimates of psychiatric disorders (Jones et al., 2010).

\section{MULTI-DIMENSIONAL DISORDER}

Depressive mood comprises vegetative symptoms (chronic fatigue, sleep disorders, anergia, reduced libido, and elevated stress); affective symptoms (feeling blue, loss of pleasure, ill temper, and irritability); behavioral changes (withdrawal from social and other activities, passive avoidance, helplessness); and cognitive alterations (rumination, hopelessness, loss of self-esteem, or feelings of guilt). Our clinical experience shows that the composition of these dimensions of depression differs between patients with epilepsy versus those without epilepsy. Depressive mood alterations in epilepsy patients often remain subsyndromic if the established psychiatric criteria of major depression are applied (Kanner et al., 2010a). In depressed epilepsy patients, the somatic and behavioral alterations appear more dominant than cognitive alterations. However, vegetative and affective symptoms might have been caused by the antiepileptic medication, and the behavior may have changed in an attempt to cope with the threat of seizures (e.g., self-protection or avoidance of embarrassing situations). This demonstrates that it is essential to take epilepsy-related factors into account when conducting a neuropsychiatric evaluation of mood states (for a different view, see Krishnamoorthy et al., 2007).

\section{EPILEPSY AS AN ETIOLOGICAL MODEL FOR DEPRESSION}

We assume that mental states (such as moods) are emergent properties of the material organism, especially the brain, which implies strong psychophysiological correlations but non-identity and irreducibility of both aspects. In keeping with this non-reductionist approach, epilepsy provides intriguing examples for both a complex psychosocial etiology of depression and for the role of intrinsic neuroetiological factors.

\section{STRESS}

Within the framework of the diathesisstress model (Monroe and Simons, 1991), depression is viewed as the result of overwhelming life challenges (i.e., stress) in combination with an individual diathesis (i.e., a disadvantageous organic or psychological disposition or vulnerability). More precisely, stress represents a psychophysiological reaction and results from an actual or perceived discrepancy between life demands and available coping resources. This concept was also addressed as allostatic load (McEwen, 1998).

Evidently, epilepsy and non-epileptic seizure disorders represent a condition with unusual and heavy life demands. The burden of epilepsy may comprise seizure-related injuries and hospitalizations, cognitive and behavioral impairments, restricted mobility, reduced educational outcomes, lower socioeconomic and marital status, and humiliatingly - social stigma (de Boer et al., 2008). The role of seizure-related stress for depression etiology is highlighted by the fact that the depression prevalence in patients with non-epileptic seizures (LaFrance and 
Syc, 2009) and for those otherwise healthy parents caring for a child with epilepsy ( $\mathrm{Lv}$ et al., 2009) is the same as that for patients with active epilepsy.

\section{LEARNED HELPLESSNESS}

Learned helplessness is still the most influential paradigm for inducing depressionlike behaviors in experimental animals (Duman, 2010). Procedures like the forced swim test comprise repeated and uncontrollable aversive, usually life-threatening stimulation. Evidently, this is the exact type of experience for patients suffering from seizures, regardless of whether they are epileptic or non-epileptic (Hermann et al., 1996). Cognitively, helplessness translates into increased external locus of control attributions and loss of the sense of internal control. Several studies confirmed causal attribution style alterations in epilepsy patients (McLaughlin et al., 2010).

\section{LOSS OF REINFORCEMENT}

The intrinsic inability to experience pleasure could be correlated with alterations of the mesocorticolimbic dopamine system, i.e., the brain's reward system (Stone et al., 2008; Martin-Soelch, 2009). However, experiences of social stigmatization or embarrassing situations related to seizures (e.g., enuresis) may reasonably result in epilepsy patients withdrawing from reinforcing social activities. In addition, the patient may have been advised to forego specific activities as they are associated with unacceptable health risks if seizures should occur (e.g., swimming). As a result, patients lose pleasant physical and social activities and this has a strong negative effect on their well-being.

\section{PERI-ICTAL DEPRESSION}

Depressive mood alterations have been reported not only as a frequent precipitant of seizures (Spector et al., 2000), but also as a symptom of prolonged (lasting over 2-3 days) postictal recovery (Kanner et al., 2010b). Of note, postictal depression with acute suicidal urge has been documented in a single case (Fincham and Anderson, 2000). For those patients who experience several seizures per month, it appears pointless to distinguish interictal from peri-ictal depression (Mula et al., 2010). Electropathophysiological alterations similar to epileptogenic abnormalities have also been stated for non-epileptic patients with major depression (Shelley et al., 2008).

\section{IATROGENIC DEPRESSION}

Depression is an important side-effect of phenobarbital (Brent et al., 1987) and primidone (Lopez-Gomez et al., 2005). Psychiatric adverse effects comprising irritability and aggressiveness have been reported for levetiracetam (Mula et al., 2003). The FDA issued a black box warning which listed an increased suicidality risk for all antiepileptic drugs (Hesdorffer and Kanner, 2009), although this is still being debated.

\section{TREATING DEPRESSION IN EPILEPSY}

The highly debated issue of antidepressant drugs versus psychotherapy for depression treatment is an empirical question of finding the safest, most effective, and most efficient way of normalizing mood regulation (i.e., restituting the ability to experience adequate affective response). In general, most experts agree with us that far more interventional therapeutic studies are required (Kanner, 2003).

\section{ANTIDEPRESSANT DRUGS}

Drug treatment for depression is not about (unethically and illegally) inducing states of happiness (or inhibiting negative feelings). Instead, and more ambitiously, medical drug treatment should aim at the restitution of normal mood regulation, i.e., the ability to experience adequate positive and negative affective response (Holtzheimer and Mayberg, 2011). However, no substantial improvement of depression treatment could be achieved during the last 50-70 years (Holtzheimer and Mayberg, 2011). According to recent meta-analyses (Ioannidis, 2008; Turner et al., 2008), serotonin reuptake inhibitors (SSRIs) showed only moderate therapeutic efficacy and then only for severe depression (which is less prevalent in epilepsy). The expanding use of antidepressants in the US over the last three decades has had no obvious effect on the suicide rates (Hu et al., 2008).

Expert recommendations for using SSRIs for treatment of depression in epilepsy (Barry et al., 2008) are based on a surprisingly sparse empirical basis (Mula and Schmitz, 2009; Hoppe and Elger, 2011). No controlled studies on currently available antidepressants have been performed in epilepsy patients. Single-arm studies indicated mood improvements, but also frequent adverse effects and relatively low therapy adherence. In many studies on epilepsy, patients using antidepressants continue to show elevated scores for depressive mood.

\section{PSYCHOTHERAPY}

Although a publication bias must also be considered for studies on psychotherapy of depression (Cuijpers et al., 2010), a moderate efficacy has been adequately shown for cognitive-behavioral therapy (CBT; DeRubeis et al., 2008), acceptance and commitment therapy (Lundgren et al., 2008), and behavioral activation therapy (Lundgren et al., 2008; Sturmey, 2009). CBT also showed efficacy in depressed patients with somatic chronic conditions (Beltman et al., 2010), including epilepsy. One study demonstrated the potential for preventing depression in adolescents with new-onset epilepsy (Martinovic et al., 2006). Currently, several clinical programs are set-up which explore different ways of offering psychotherapeutic support to epilepsy patients, including the use of web-based technologies (Thompson et al., 2010).

\section{NON-MEDICAL PROFESSIONAL SUPPORT}

According to our reading of the diathesisstress model, stress occurs as a result of both objective life demands and disadvantageous personal disposition. Consequently, patient support should also address real life conditions, which is beyond the scope of medical health care professionals. Rehabilitative care programs and counseling by social workers and psychologists may contribute toward improving the familial situation, personal relationships, job or educational affairs, and leisure activities - all of which is promising to decrease stress (Ridsdale, 2009). In addition, psychological training (apart from therapy) may improve the coping skills as well as the compensation of cognitive deficits affecting daily life.

\section{CONCLUSION: EMOTIONAL WELL- BEING IN EPILEPSY}

The challenge of supporting patients with epilepsy is enabling them to maintain or restitute their emotional well-being and life satisfaction when dealing with seizures which are, as of yet, untreatable. This requires a complex adaptation of attitudes 
and behaviors of patients and affected families toward actively coping with the given situation; adequate use of medical and nonmedical support; strengthening resilience; and maintaining (or restituting) pleasant activities. Many patients will find their way with support of their families and friends while others rely on their doctor's advice, psychotherapy, or patient groups.

Antiepileptic drug treatment eventually must be reconsidered with regard to possible psychiatric side effects and possible seizure-related impairments of mood regulation. Even if more evidence is required for the efficacy and safety of antidepressive drugs, experts consistently recommend their use in depressed epilepsy patients based on clinical experience. In general, drugs might contribute to but will probably not replace the difficult process of adjusting the conduct of life to the conditions of active epilepsy.

\section{REFERENCES}

Barry, J. J., Ettinger, A. B., Friel, P., Gilliam, F. G., Harden, C. L., Hermann, B., Kanner, A. M., Caplan, R., Plioplys, S., Salpekar, J., Dunn, D., Austin, J., and Jones, J. (2008). Consensus statement: the evaluation and treatment of people with epilepsy and affective disorders. Epilepsy Behav. 13, S1-S29.

Beltman, M. W., Voshaar, R. C., and Speckens, A. E. (2010). Cognitive-behavioural therapy for depression in people with a somatic disease: meta-analysis of randomised controlled trials. Br. J. Psychiatry 197, 11-19.

Brent, D. A., Crumrine, P. K., Varma, R. R., Allan, M., and Allman, C. (1987). Phenobarbital treatment and major depressive disorder in children with epilepsy. Pediatrics 80, 909-917.

Cuijpers, P., Smit, F., Bohlmeijer, E., Hollon, S. D., and Andersson, G. (2010). Efficacy of cognitive-behavioural therapy and other psychological treatments for adult depression: meta-analytic study of publication bias. Br. J. Psychiatry 196, 173-178.

de Boer, H. M., Mula, M., and Sander, J. W. (2008). The global burden and stigma of epilepsy. Epilepsy Behav. 12, 540-546.

DeRubeis, R. J., Siegle, G. J., and Hollon, S. D. (2008). Cognitive therapy versus medication for depression: treatment outcomes and neural mechanisms. Nat. Rev. Neurosci. 9, 788-796.

Duman, C. H. (2010). Models of depression. Vitam. Horm. 82, 1-21.

Fincham, R., and Anderson, S. (2000). Postictal depression following subtle seizures. Epilepsy Behav. 1, 278-280.

Hermann, B. P., Trenerry, M. R., and Colligan, R. C. (1996). Learned helplessness, attributional style, and depression in epilepsy. Bozeman epilepsy surgery consortium. Epilepsia 37, 680-686.
Hesdorffer, D. C., and Kanner, A. M. (2009). The FDA alert on suicidality and antiepileptic drugs: fire or false alarm? Epilepsia 50, 978-986.

Holtzheimer, P. E., and Mayberg, H. S. (2011). Stuck in a rut: rethinking depression and its treatment. Trends Neurosci. 34, 1-9.

Hoppe, C., and Elger, C. E. (2011). Depression in epilepsy: a critical review from a clinical perspective. Nat. Rev. Neurol. 7, 462-472.

Hu, G., Wilcox, H. C., Wissow, L., and Baker, S. P. (2008). Mid-life suicide: an increasing problem in U.S. Whites, 1999-2005. Am. J. Prev. Med. 35, 589-593.

Ioannidis, J. P. (2008). Effectiveness of antidepressants: an evidence myth constructed from a thousand randomized trials? Philos. Ethics Humanit. Med. 3, 14.

Jones, R., Rickards, H., and Cavanna, A. E. (2010). The prevalence of psychiatric disorders in epilepsy: a critical review of the evidence. Funct. Neurol. 25, 191-194.

Kanner,A.M. (2003). Depression in epilepsy: prevalence, clinical semiology, pathogenic mechanisms, and treatment. Biol. Psychiatry 54, 388-398.

Kanner, A. M., Barry, J. J., Gilliam, F., Hermann, B., and Meador, K. J. (2010a). Anxiety disorders, subsyndromic depressive episodes, and major depressive episodes: do they differ on their impact on the quality of life of patients with epilepsy? Epilepsia 51, 1152-1158.

Kanner, A. M., Trimble, M., and Schmitz, B. (2010b). Postictal affective episodes. Epilepsy Behav. 19, 156-158.

Krishnamoorthy, E. S., Trimble, M. R., and Blumer, D. (2007). The classification of neuropsychiatric disorders in epilepsy: a proposal by the ILAE commission on psychobiology of epilepsy. Epilepsy Behav. 10,349-353.

LaFrance, W. C. Jr., Kanner, A. M., and Hermann, B. (2008). Psychiatric comorbidities in epilepsy. Int. Rev. Neurobiol. 83, 347-383.

LaFrance, W. C., and Syc, S. (2009). Depression and symptoms affect quality of life in psychogenic nonepileptic seizures. Neurology 73, 366-371.

Lopez-Gomez, M., Ramirez-Bermudez, J., Campillo, C., Sosa, A. L., Espinola, M., and Ruiz, I. (2005). Primidone is associated with interictal depression in patients with epilepsy. Epilepsy Behav. 6, 413-416.

Lundgren, T., Dahl, J., and Hayes, S. C. (2008). Evaluation of mediators of change in the treatment of epilepsy with acceptance and commitment therapy. J. Behav. Med. 31, 225-235.

Lv, R., Wu, L., Jin, L., Lu, Q., Wang, M., Qu, Y., and Liu, H. (2009). Depression, anxiety and quality of life in parents of children with epilepsy. Acta Neurol. Scand. 120, 335-341.

Martinovic, Z., Simonovic, P., and Djokic, R. (2006). Preventing depression in adolescents with epilepsy. Epilepsy Behav. 9, 619-624.

Martin-Soelch, C. (2009). Is depression associated with dysfunction of the central reward system? Biochem. Soc. Trans. 37, 313-317.

McEwen, B. S. (1998). Stress, adaptation, and disease. Allostasis and allostatic load. Ann. N. Y. Acad. Sci. 840, 33-44.

McLaughlin, D. P., Pachana, N. A., and McFarland, K. (2010). The impact of depression, seizure variables and locus of control on health related quality of life in a community dwelling sample of older adults. Seizure 19, 232-236.
Monroe, S. M., and Simons, A. D. (1991). Diathesis-stress theories in the context of life stress research: implications for the depressive disorders. Psychol. Bull. 110, 406-425.

Mula, M., Jauch, R., Cavanna, A., Collimedaglia, L., Barbagli, D., Gaus, V., Kretz, R., Viana, M., Tota, G., Israel, H., Reuter, U., Martus, P., Cantello, R., Monaco, F., and Schmitz, B. (2008). Clinical and psychopathological definition of the interictal dysphoric disorder of epilepsy. Epilepsia 49, 650-656.

Mula, M., Jauch, R., Cavanna, A., Gaus, V., Kretz, R., Collimedaglia, L., Barbagli, D., Cantello, R., Monaco, F, and Schmitz, B. (2010). Interictal dysphoric disorder and periictal dysphoric symptoms in patients with epilepsy. Epilepsia 51, 1139-1145.

Mula, M., and Schmitz, B. (2009). Depression in epilepsy: mechanisms and therapeutic approach. Ther. Adv. Neurol. Disord. 2, 337-344.

Mula, M., Trimble, M. R., Yuen, A., Liu, R. S., and Sander, J. W. (2003). Psychiatric adverse events during levetiracetam therapy. Neurology 61, 704-706.

Reynolds, E. H., and Trimble, M. R. (2009). Epilepsy, psychiatry, and neurology. Epilepsia 50(Suppl. 3), 50-55.

Ridsdale, L. (2009). The social causes of inequality in epilepsy and developing a rehabilitation strategy: a U.K.-based analysis. Epilepsia 50, 2175-2179.

Shelley, B. P., Trimble, M. R., and Boutros, N. N. (2008). Electroencephalographic cerebral dysrhythmic abnormalities in the trinity of nonepileptic general population, neuropsychiatric, and neurobehavioral disorders. J. Neuropsychiatry Clin. Neurosci. 20, 7-22.

Spector, S., Cull, C., and Goldstein, L. H. (2000). Seizure precipitants and perceived self-control of seizures in adults with poorly-controlled epilepsy. Epilepsy Res. 38, 207-216.

Stone, E. A., Lin, Y., and Quartermain, D. (2008). A final common pathway for depression? Progress toward a general conceptual framework. Neurosci. Biobehav. Rev. 32, 508-524.

Sturmey, P. (2009). Behavioral activation is an evidencebased treatment for depression. Behav. Modif. 33, 818-829.

Thompson, N. J., Walker, E. R., Obolensky, N., Winning, A., Barmon, C., Diiorio, C., and Compton, M. T. (2010). Distance delivery of mindfulness-based cognitive therapy for depression: project UPLIFT. Epilepsy Behav. 19, 247-254.

Turner, E. H., Matthews, A. M., Linardatos, E., Tell, R. A., and Rosenthal, R. (2008). Selective publication of antidepressant trials and its influence on apparent efficacy. N. Engl. J. Med. 358, 252-260.

Received:09September 2011; accepted: 21 November 2011; published online: 07 December 2011.

Citation: Elger CE and Hoppe C (2011) What is depression in epilepsy? Front. Neur. 2:79. doi: 10.3389/fneur.2011.00079 This article was submitted to Frontiers in Epilepsy, a specialty of Frontiers in Neurology.

Copyright (c) 2011 Elger and Hoppe. This is an openaccess article distributed under the terms of the Creative Commons Attribution Non Commercial License, which permits non-commercial use, distribution, and reproduction in other forums, provided the original authors and source are credited. 